\title{
Dewatering tailings: rapid water recovery by use of centrifuges
}

\author{
R Klug Flottweg SE, Germany \\ N Schwarz Schwarz Global Consulting (Pty) Ltd, South Africa
}

\begin{abstract}
At present, most tailings are dewatered by static settling in tailings dams. The environmental impact of these large settlings ponds is very dramatic, not to mention the space requirements and the potential risk of dam failure. This method of disposal also results in the loss of process water due to evaporation. This can be significant in areas where the supply of fresh water is limited.

The high centrifugal force in a decanter centrifuge drastically increases dewatering efficiency, as centrifugal separation happens at up to $29,430 \mathrm{~m} / \mathrm{s}^{2}$ (3,000 $\times$ gravitational acceleration or $\mathrm{g}$ ).

Depending on the material, more than $90 \%$ of the process water can be recovered using centrifuge technology. It can be reused in the mineral processing operation and will increase the water efficiency of the whole mining community.
\end{abstract}

This paper presents the results of actual projects in Brazil and Peru.

Keywords: tailings, dewatering, dry stacking, centrifuge, decanter

\section{$1 \quad$ Introduction}

Mine tailings are the ore waste of mines and are typically a mud-like material. Worldwide, the storage and handling of tailings can an environmental issue if not managed properly. Many tailings are toxic and must be kept perpetually isolated from the environment. The scale of tailings production can be immense, since metal extraction is only a fraction of every tonne of ore processed. Tailings containment facilities are regarded to be among the world's largest man-made objects.

\subsection{Wet storage in pits and lakes}

Most modern hard rock metal mines dispose of tailings as a wet slurry, contained in impoundments lined with clay or a synthetic liner, as seen in Figure 1. Many mines put a portion of the tailings back into the original mining pit. Some large mines use entire existing valleys sealed off with earthen dams, and others store tailings in natural lakes. In some cases, disposal sites are covered with water, forming an artificial lake. This reduces the rate of acid formation, as it minimises oxygen diffusion to the potential acid forming minerals in the tailings.

Wet storage often requires long-term oversight, to monitor and attempt to mitigate contaminated groundwater movement, and to maintain any crucial facilities, such as dams. Many wet storage facilities require perpetual water treatment, as some degree of seepage is inevitable. This is exacerbated in cases where heavy rainfall can lead to potential overflow of the tailings dam. 


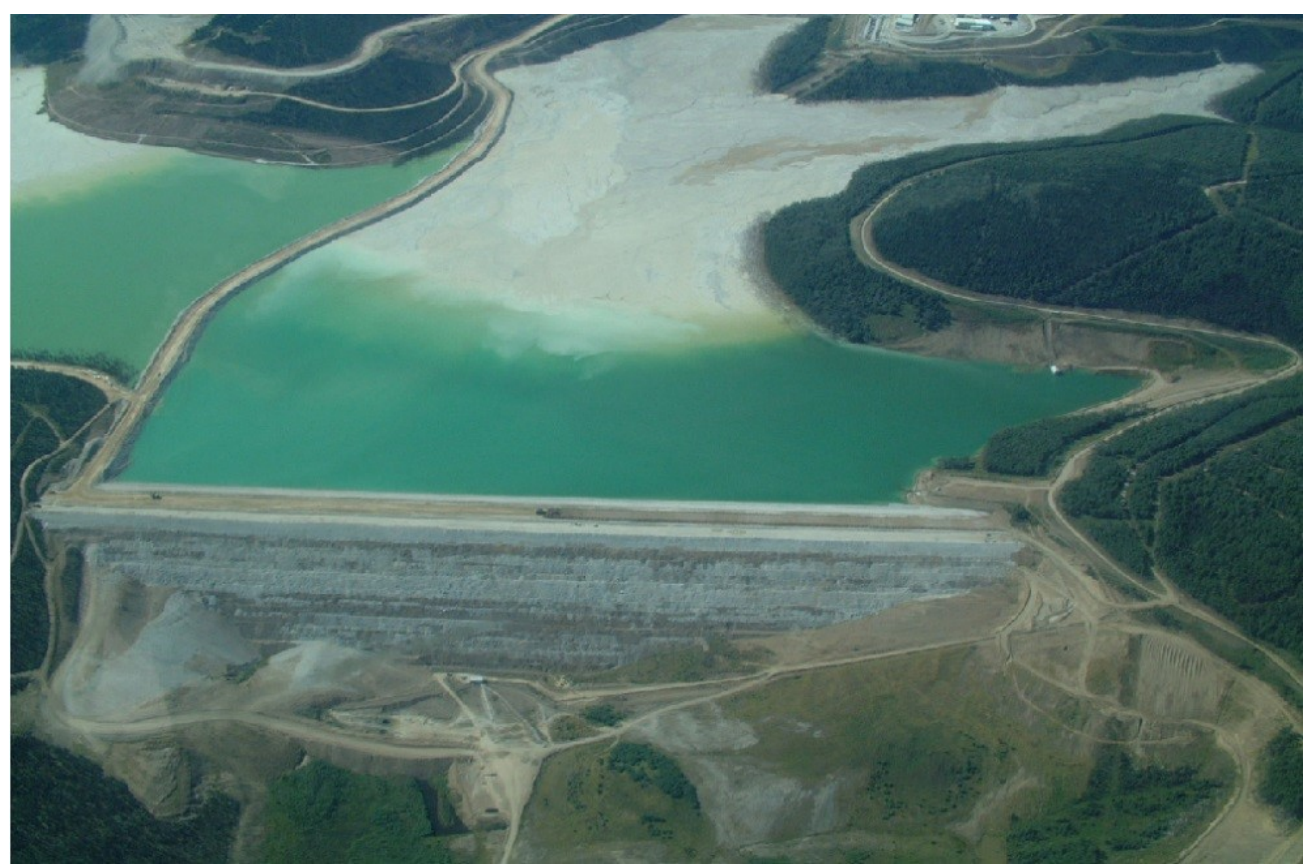

Figure 1 Wet tailings dam at Fort Knox mine near Fairbanks (Patagonia Under Siege 2018)

\subsection{Filtered and stackable tailings storage}

In the case of dry stacking, tailings are stored in dry form, typically by burial in a covered and lined pit. In this regard, the storage method is similar to a modern, sealed landfill. This method takes up much less space, is less susceptible to earthquake hazards, and does not require active water treatment. This makes it particularly relevant in locations where the risk of overtopping by precipitation or earthquake risks are high, or in mountainous regions where space is limited, as seen on Figure 2. As most of the process water is recovered from these tailings, this method of tailings disposal is also particularly suited to arid regions, where reduced water losses are desirable.

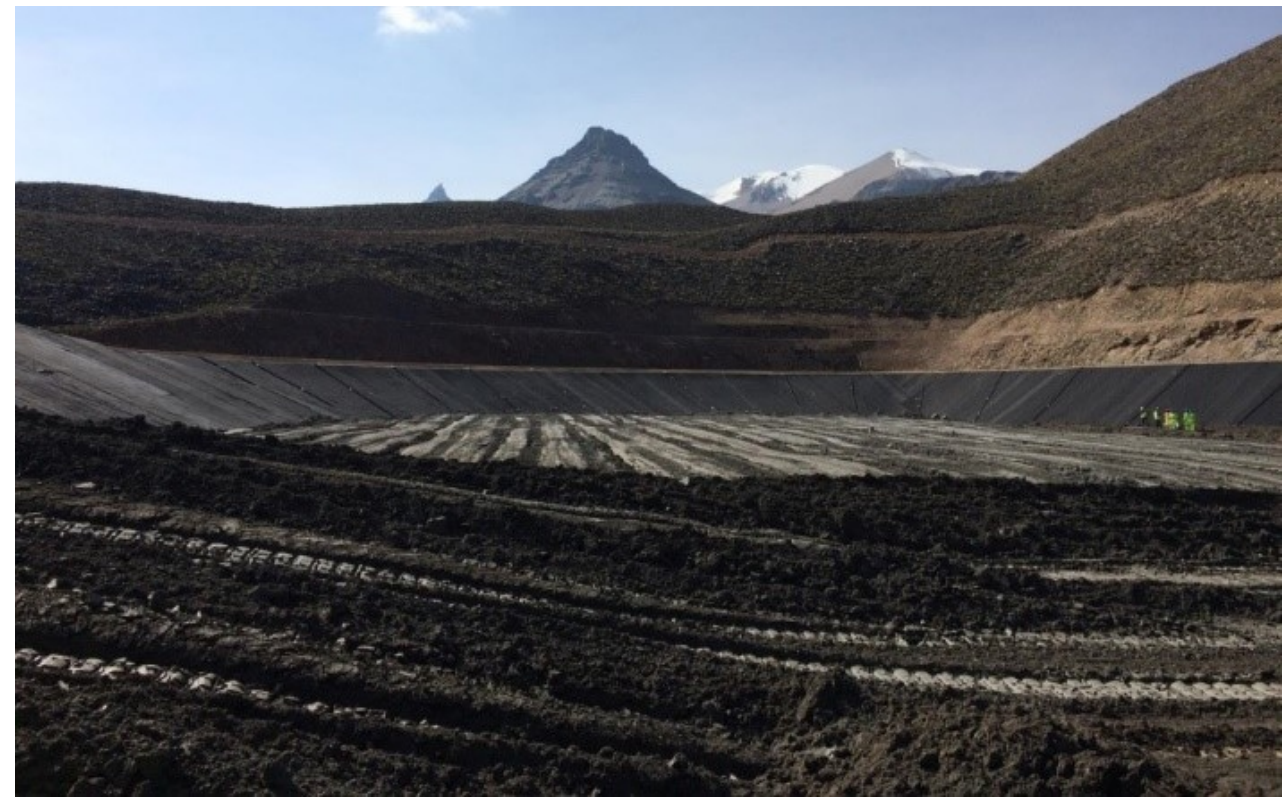

Figure 2 Dry tailings facility 
Dry stacking of tailings does, however, have much higher upfront costs than wet storage. Tailings must be dewatered further, and the solid tailings must be transported by truck or conveyor instead of by slurry pipeline, which adds logistical complexity and cost.

However, dry stacking simplifies the maintenance of tailings storage facilities. In some cases, where the material dewaters well, the tailings can even be stored in stable deposits requiring no retention bonding.

\section{Dewatering of tailings}

Tailings do not have to be stored in ponds or sent as slurries into oceans, rivers or streams. There is a growing use of the practice of dewatering tailings using vacuum or pressure filters, so the tailings can then be stacked (Davies \& Rice 2001). This saves water which potentially reduces the impacts on the environment in terms of a reduction in the potential seepage rates and space used. It leaves the tailings in a dense and stable form and eliminates the long-term liability that ponds leave after mining is finished. While there are potential merits to dry-stacked tailings, these systems are often cost-prohibitive due to increased capital cost to purchase and install the filter systems and the increase in operating costs (generally associated electricity consumption and consumables such as filter cloth) of such systems.

\subsection{Alternative technologies to dewater tailings}

In a tailings dam, the solids are settled by sedimentation, so the force on the sediments is the natural earth gravity. Several technologies are available to speed up the dewatering.

\subsubsection{Recessed chamber pressure filters}

Recessed chamber pressure filters are made up of polypropylene chambers and are fed by a feed pump that provides the hydraulic head for the dewatering. Two plates join to form a chamber; the pressurised slurry is fed to the chambers and squeezes the filtrate out through the filter cloth lining in the chamber.

As the filter cake becomes thicker, the filter resistance increases, so increased pump power is required.

When the chamber is full, the filtration process is stopped (that is, when the optimum pressure difference is reached). The filtrate that passes through the filter cloth is collected through collection pipes. The plates of the filter press are then pulled apart and the cake that accumulated in the recessed chamber falls out, to be discharged to the final collection point. Cake discharge can be done in many ways, for example, by shaking the plates while they are being opened or shaking the cloths. Scrapers can also be used, by moving from one chamber to another and scraping the cake off the cloth. The cloth needs to be cleaned regularly using wash liquid. The disadvantage of using recessed chamber pressure filter is the batch operation of charge and discharge, as seen in Figure 3.

Some filter presses add post-filtration capabilities, like air core blow, or inflating membranes to squeeze the cake to further reduce its residual moisture.

While the use of recessed chamber pressure filters for tailings dewatering was mentioned as early as 1903, only in the 1980s was it put into large-scale commercial practice. By 2011, filter presses had become more common. 


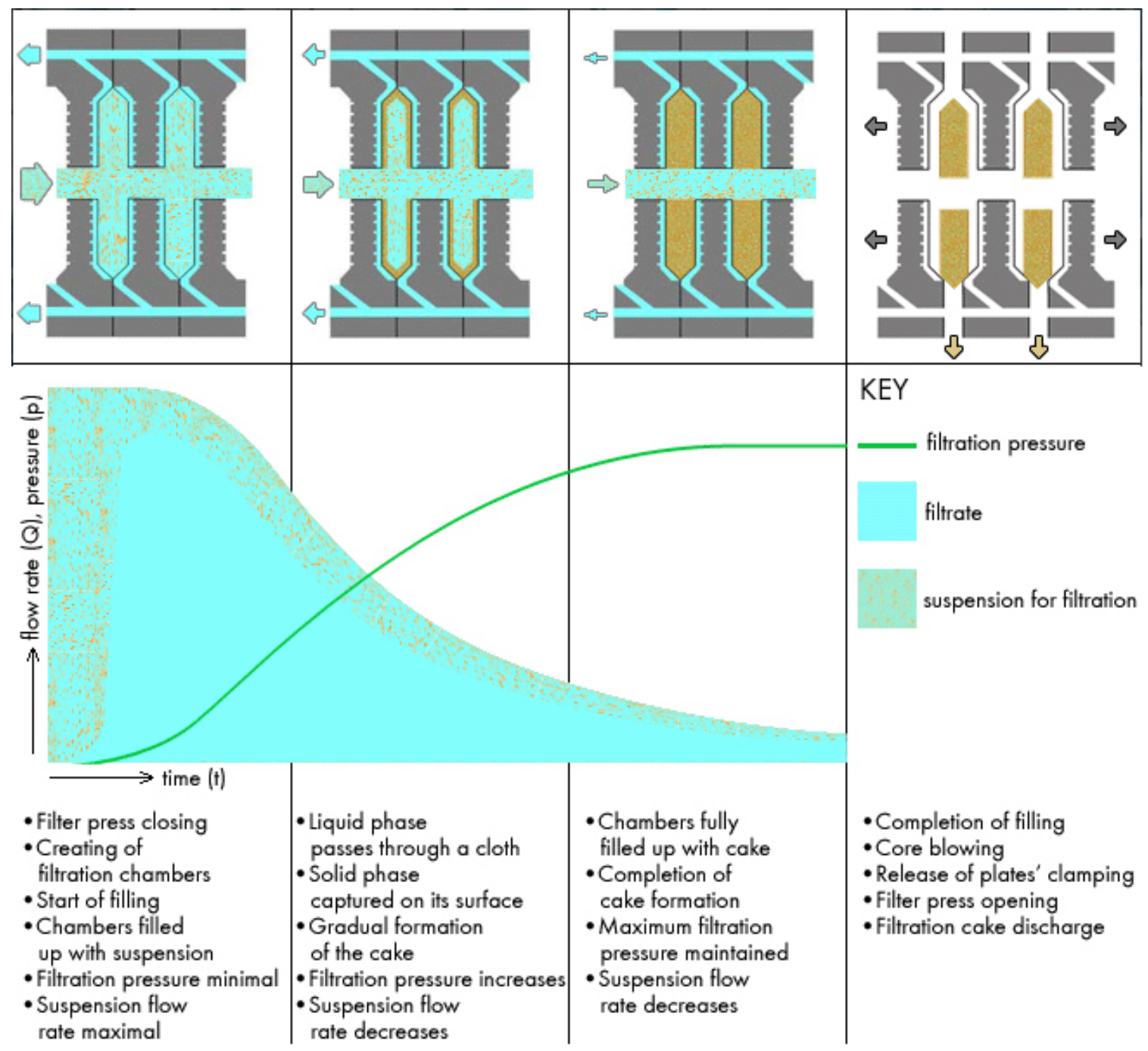

Figure 3 Operation of recessed chamber pressure filter used for dewatering sludge (ENVITES, spol. s r.o. 2019)

\subsubsection{Centrifuges}

Mechanical separation technology by centrifuge was developed around 100 years ago. This is a modern technology that allows a continuous processing of sludge. In a centrifuge, the solids are affected by centrifugal force. Centrifugal force is linked to two parameters: distance to the rotating axis, and the speed of rotation. Today, centrifugal forces of $29,420 \mathrm{~m} / \mathrm{s}^{2}(3,000 \times \mathrm{g})$ are typical, to dewater all kinds of sludge.

A cut-away diagram of a decanter centrifuge is shown in Figure 4. This is the type of centrifuge that would typically be used for dewatering fine mineral materials such as tailings, as it provides continuous processing and can handle much higher throughputs than discontinuous machines such as peeler centrifuge.

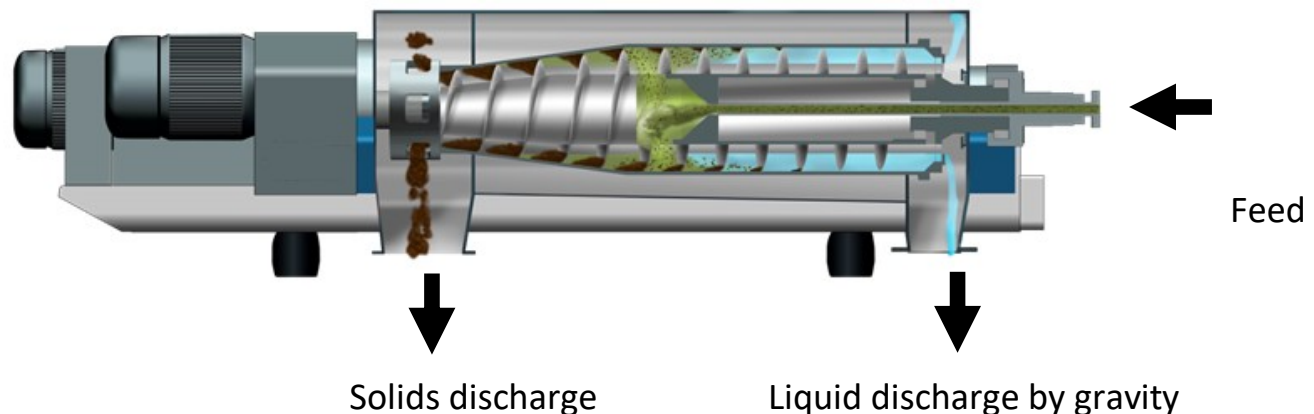

Figure 4 Cut-away of solid bowl decanter centrifuge 
In a centrifuge, the sludge is continuously pumped into the feed pipe and enters through the feed chamber into the fast-rotating rotor.

The centrifugal force causes the sludge to form a ring inside of the rotor. As the density of the solids is higher than the liquid density, the solids will settle on the inside wall of the rotor. To remove the settled solids, a scroll rotates inside the rotor, with a differential speed towards the rotor, and picks up the accumulated solids.

The bowl is tapered towards the solids discharge of the centrifuge so, at a certain point, the solids will leave the liquid zone and will pass the 'beach area' into the dry area. Here, the solids dewater further until they are discharged through ports via centrifugal force. As the discharge diameter is smaller than the diameter of the liquid discharge, the liquid (centrate) can only exit the rotor on the liquid discharge side.

\subsection{The effect of using centrifuges}

\subsubsection{Dewatering results}

The solids content achievable in the solid discharge of a centrifuge and a chamber filter press are very similar, as illustrated in Figure 5. A centrifuge will usually capture all particles above $5 \mu \mathrm{m}$ in size. The use of a suitable flocculant is necessary to capture the ultra-fine parts if clean centrate is required. While the actual residual moisture achievable for any application is dependent on a number of factors such as the presence of hydrolysed components, in the case of mineral tailings it is strongly dependent on the particle size distribution of the solids. The finer the particle size range, the more moisture will be entrained. Typically, the solids discharged would have a crumbly consistency, and no free moisture.

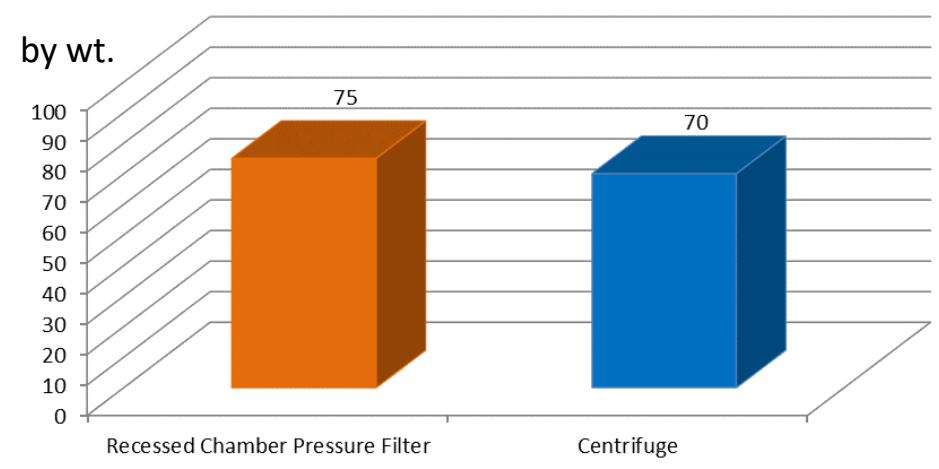

(a)

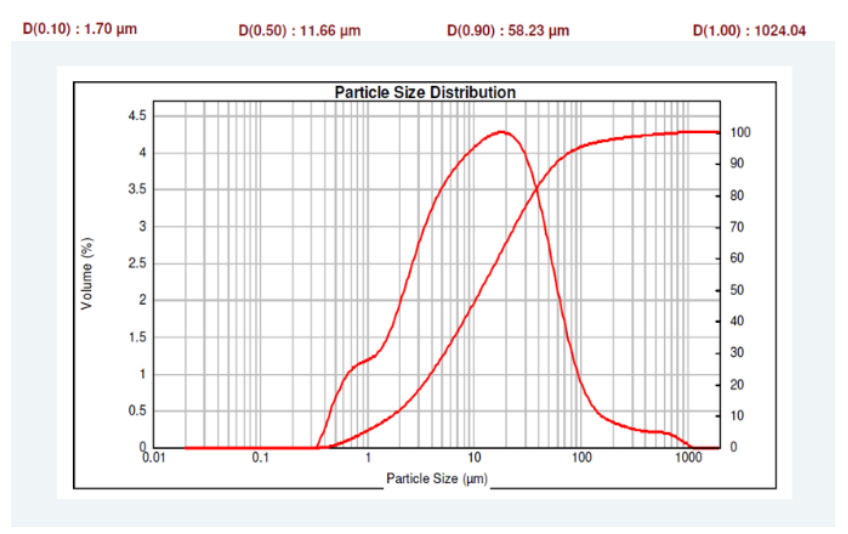

(b)

Figure 5 Typical tailings dewatering results in a gold mining operation. (a) Percent of dry solids (DS) after dewatering; and (b) Particle size distribution 


\subsubsection{Separation efficiency}

Figure 6 shows the drastic volume reduction of the tailings sludge that is achievable with a centrifuge and the typical quality of the centrate recovered. One specific advantage that a decanter centrifuge has over filters is that there is no filter cloth that can become blinded with fine particles. This means that the flow rate through a centrifuge will remain constant.
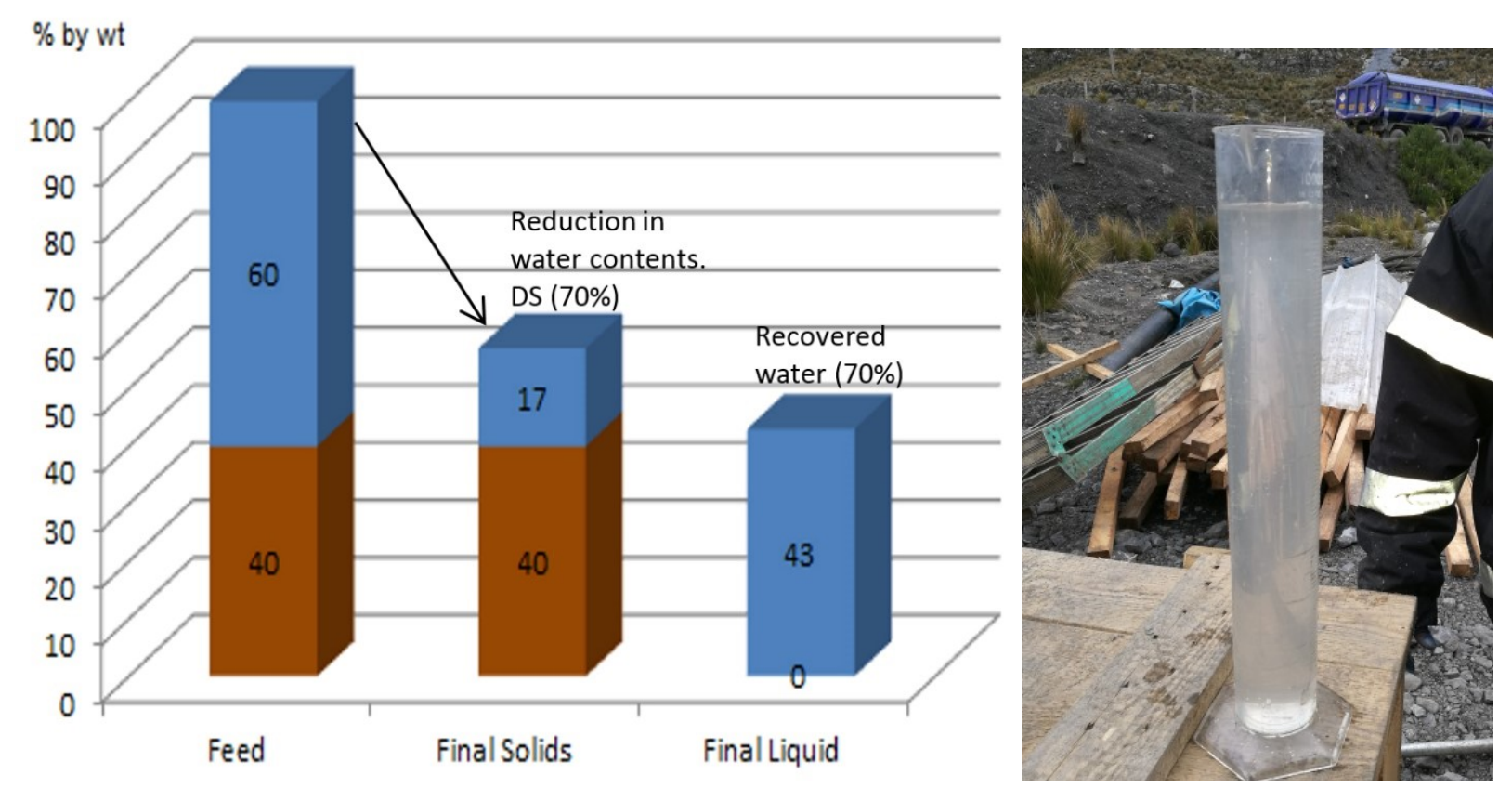

Figure 6 Typical change between tailings feed and discharge of solids and liquid in a gold mining operation, and resultant centrate quality

\section{Application example of centrifuge use for mine tailings}

\subsection{Case study: Buenaventura, Peru}

The gold mine Buenaventura Tambomayo is located in the area of Arequipa at an altitude of 4,800 m. The main issue at this mine is that space is very limited, and the environmental agency has a close eye on water consumption as well on liquid discharge.

In order to meet the environmental regulations, Buenaventura installed two large filter presses to treat $1,500 \mathrm{t} \mathrm{DS} /$ day, as shown in Figure 7. Each filter press had 91 plates, $3 \times 3 \mathrm{~m}$ each. Cycle time was to be 17 minutes: 5 minutes loading, 5 minutes pressing and 7 minutes discharge. Washing of the cloths was intended to be done once per week, with only one operator required per shift.

After commissioning, it was found that the chamber filter presses only reached a capacity of about $20 \mathrm{t} \mathrm{DS} / \mathrm{hr}$ each, which added up to less than 1,000 t DS/day. Cycle time was increased to 22 mins, washing of the cloth had to be done twice per day and 10 workers were required to discharge the filter cakes in two filter presses. Because the mine did not have a wet tailings dam facility, it had to cut production to be in line with the capacity of the chamber filter presses. 

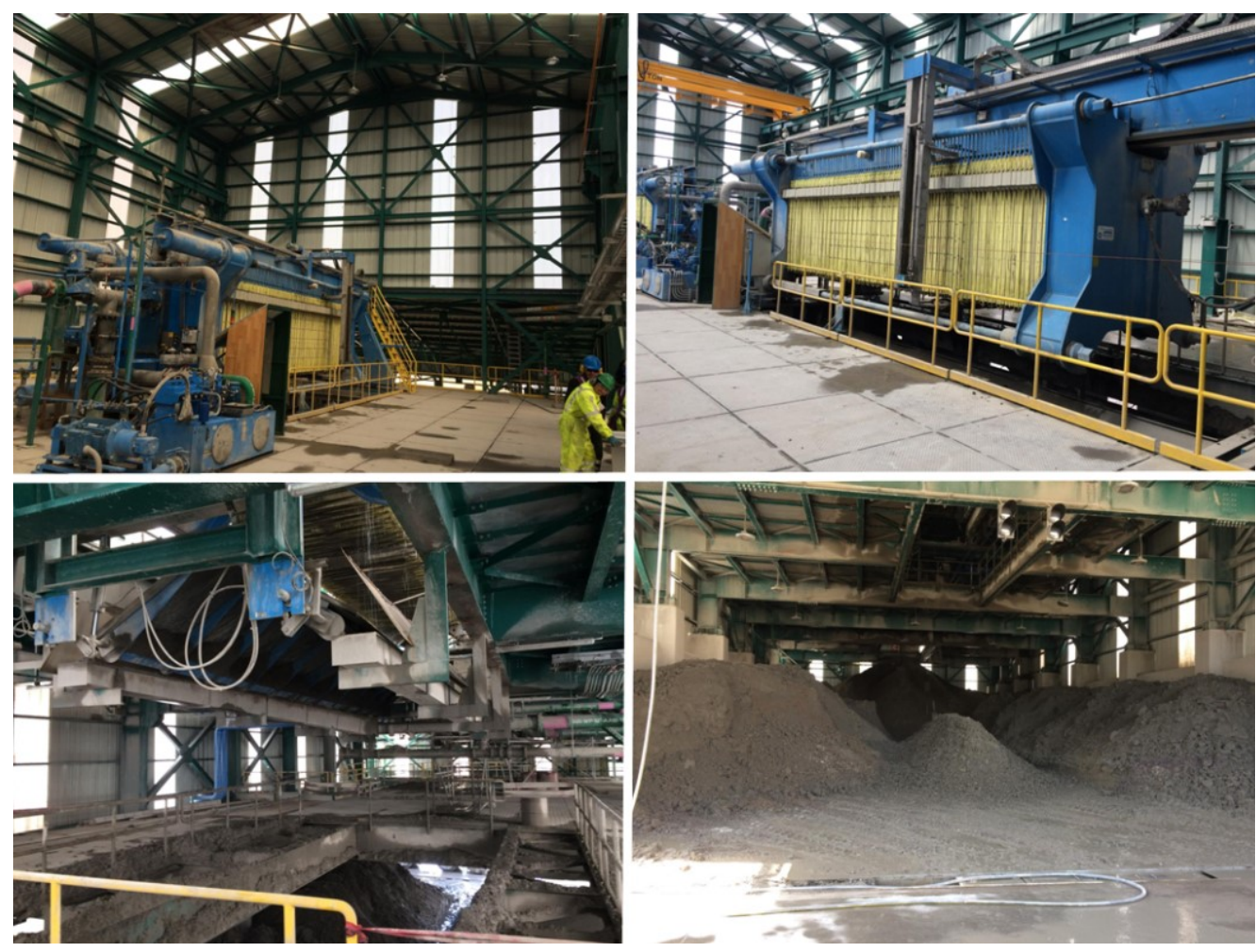

Figure 7 Multi-storey filter press building at Buenaventura's Tambomayo mine

The centrifuge shown in Figure 8 was moved from successful trials at another Buenaventura mine to Tambomayo. Its installation and commissioning took just three weeks. It was installed on a $2 \mathrm{~m}$ high steel structure and the solid discharge was transported by two belt conveyors to a truck loading site. Feed, with a solid contents of about $45 \%$ DS, was taken from the nearby thickener. The solid contents in the discharge of the centrifuge ranges from 67 to $70 \%$. The recovered centrate is clear. Nominal capacity is about $600 \mathrm{t} /$ day.

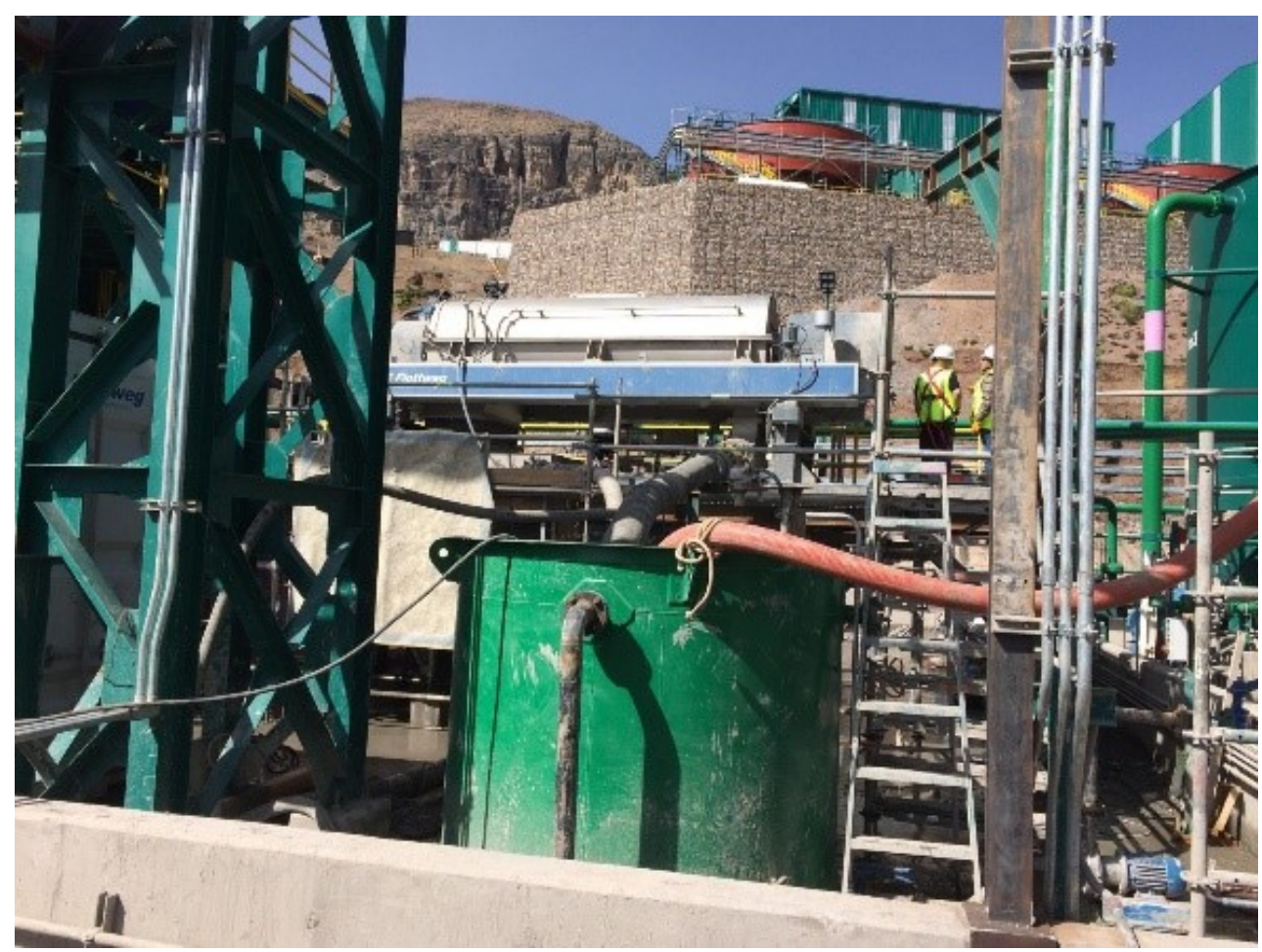

Figure 8 Centrifuge installation at Buenaventura Tambomayo mine 
The tailings are transported by truck to a dry stacking facility about $10 \mathrm{~km}$ away from the process centre; the centrate is reused in the processing facility. Photos of the solid and liquid discharge are shown in Figure 9. The operating parameters of the centrifuge are shown in Table 1 . The particle size analysis of the solids is shown in Figure 10.
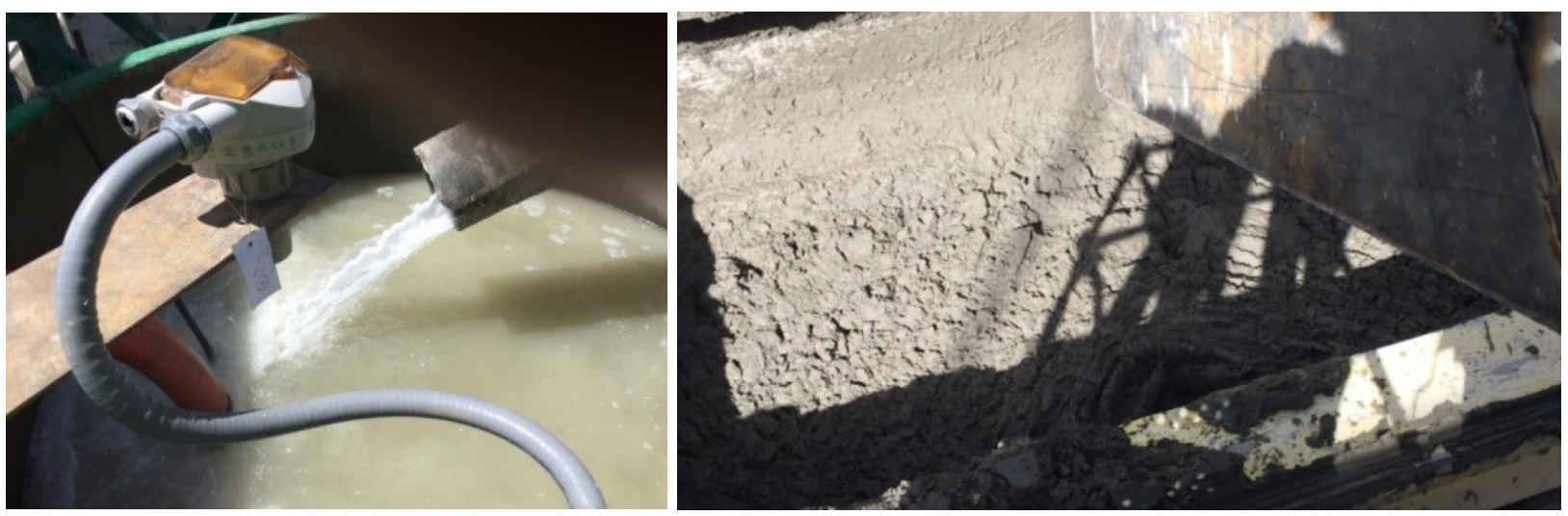

Figure 9 Liquid and solid discharge of centrifuge

\begin{tabular}{|c|c|}
\hline Analysis & Result \\
\hline $\begin{array}{l}\text { Sample Name Buenaventura_Probe } \\
\text { 7_originalprobe_US_30sec_100\% }\end{array}$ & $\begin{array}{l}\text { Concentration } 0,0087 \% \\
\text { Specific Surface Area } 1064 \mathrm{~m}^{2} / \mathrm{kg}\end{array}$ \\
\hline Measurement Date Time 02.03.2017 16:37:19 & $\mathrm{D}[3 ; 2] 5,64 \mu \mathrm{m}$ \\
\hline Particle Refractive Index 1,530 & D $[4 ; 3] 24,3 \mu \mathrm{m}$ \\
\hline Particle Absorption Index 0,100 & Dv (10) $2,09 \mu \mathrm{m}$ \\
\hline Dispersant Name Water & Dv (50) $14,0 \mu \mathrm{m}$ \\
\hline Dispersant Refractive Index 1,330 & Dv (75) $28.5 \mu \mathrm{m}$ \\
\hline Scattering Model Mie & Dv (90) $57,8 \mu \mathrm{m}$ \\
\hline Analysis Model General Purpose & Dv (100) $239 \mu \mathrm{m}$ \\
\hline Weighted Residual $0,82 \%$ & Volume Below (75) $\mu \mathrm{m} 93,03 \%$ \\
\hline Laser Obscuration $11,13 \%$ & \\
\hline
\end{tabular}

The sample was treated with ultrasonics for 30 seconds.
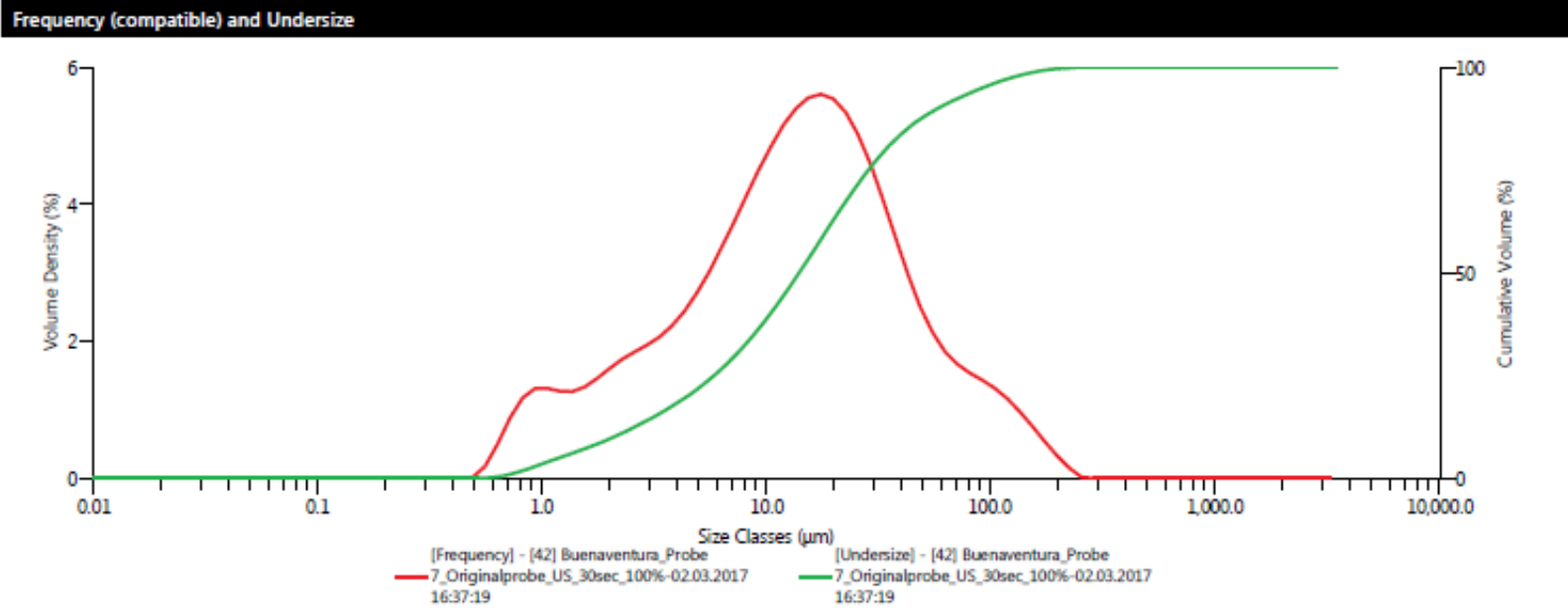

Figure 10 Particle size distribution (feed) 
Table 1 Operating parameters at Tambomayo mine

\begin{tabular}{ll}
\hline Parameter & Value \\
\hline Feed flow rate & Up to $100 \mathrm{~m}^{3} / \mathrm{hr}$ \\
Feed solids concentration & $45 \%$ (by wt) \\
Solids feed rate & Up to $39.5 \mathrm{t} / \mathrm{hr}$ \\
Drum speed & $925 \mathrm{rpm}$ \\
Centrifugal force & $4,320 \mathrm{~m} / \mathrm{s}^{2}(440 \times \mathrm{g})$ \\
Solids in centrate & $<500 \mathrm{ppm}$ \\
Solids concentration in cake & $66-70 \%($ by mass) \\
Operational power & $35 \mathrm{~kW}$ main drive, \\
consumption & $30 \mathrm{~kW}$ scroll drive \\
Flocculant consumption & $0.05-0.15 \mathrm{~kg} / \mathrm{t}$ dry matter \\
\hline
\end{tabular}

Figure 11 shows the results achieved by the decanter centrifuge. The impact of the installation of the centrifuge at Tambomayo has been significant for Buenaventura. The minimal requirement for civil infrastructure and small footprint made it possible to deploy the centrifuge rapidly, even though Tambomayo had never planned for a centrifuge installation.

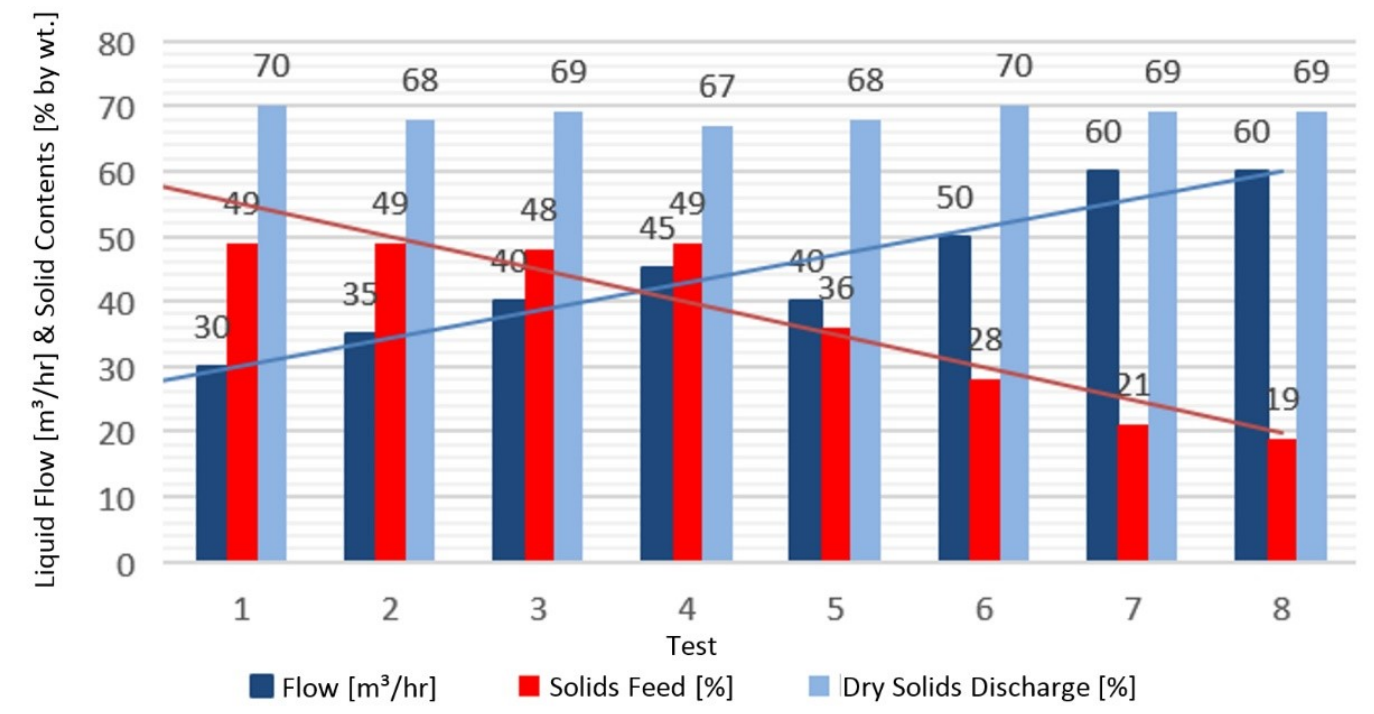

Figure 11 Overview of test result at Tambomayo mine

Although Tambomayo was inexperienced in the use of centrifuges, the machine was very easy to run with minimal staff requirements. The normal daily operational throughput exceeded that of one of the existing filter presses, averaging $600 \mathrm{t} / \mathrm{d}$ of DS. At one stage, both filter presses had to be taken offline for maintenance, and the centrifuge was able to handle the throughput of both filter presses, enabling operations to continue.

Unfortunately, by the time the centrifuge arrived at Tambomayo, Buenaventura had already ordered an additional filter press. With the planned increase in throughput at Tambomayo, the additional capacity of the third filter press will also be exceeded and the centrifuge will continue to be used. Table 2 shows a comparison between the filter presses and the centrifuge, based on information provided by Buenaventura. 
Table 2 Comparison of chamber filter press and centrifuge technologies based on long-term business experience

\begin{tabular}{lll}
\hline Parameter & Chamber filter press & Centrifuge \\
\hline Process & Discontinuous & Continuous (24/7) \\
Filtration area $\left(\mathrm{m}^{2}\right.$ ) & $100-1,000$ & - \\
Filtration volume $\left(\mathrm{m}^{3}\right.$ ) & Up to 20 & Up to 1 \\
Capacity (t DS/hr) & Up to 100 & Up to 30 \\
Comparison at equal capacity/day & & \\
Investment cost & $100 \%$ & $60 \%$ \\
Space & $100 \%$ & $20 \%$ \\
Structural support & $100 \%$ & $20 \%$ \\
Extras (crane, etc.) & $100 \%$ & $20 \%$ \\
Cycle time (min) & $17-22$ & Continuous \\
Operating personal (per 8 hr) & $4-8$ & 1 \\
Maintenance & Regular maintenance & Regular \\
- & Washing of filter cloths 1-2x/d & - \\
\hline & Change of filter cloths 2-4x/a & - \\
Downtime for maintenance (d/a) & 30 & 5 \\
Maintenance costs & $100 \%$ & $5 \%$ \\
Instrumentation (qty) & $>50$ & 5 \\
Exposure to workers & Yes & No \\
Feed pump pressure (bar) & $6-15$ & $1-2$ \\
Pre-thickening required & Yes & No \\
Dewatering results & $100 \%$ & $90 \%$ \\
Compressed air supply & Yes & No \\
Fresh water supply (day) & $100 \%$ & $0-5 \%$ \\
Required power (kW) & $100 \%$ & $100 \%$ \\
Outdoor installation possible & No & Yes \\
OPEX (USD/t DS) & $4-6$ & \\
\hline & & -4 \\
\hline & & \\
\hline
\end{tabular}

\subsection{Case study: Lipari, Brazil}

Lipari is operating the Braúna diamond mine, about $400 \mathrm{~km}$ northwest of Salvador de Bahia. It is the first diamond mine in South America developed on a kimberlite deposit. The open pit mine feeds $2,000 \mathrm{t} / \mathrm{d}$ of ore to the processing plant. The mine operates on a 24 hours a day, 7 days a week basis. The area where it is located is very dry and fresh water is supplied from a nearby river, which runs dry for three months/year. The government requires a water recovery of $>80 \%$ to keep the mine operational. The tailings at Braúna are fed to a hydrocyclone that takes out coarse particles. These are further dewatered over a vibrating screen. The overflow from the hydrocyclone and filtrate from the screen are sent to a thickener. The underflow of the thickener is fed to the decanter centrifuge. The installed centrifuge can be seen in Figure 12, while the feed material and the centrate can be seen in Figure 13. The centrate is sent back into the process. 


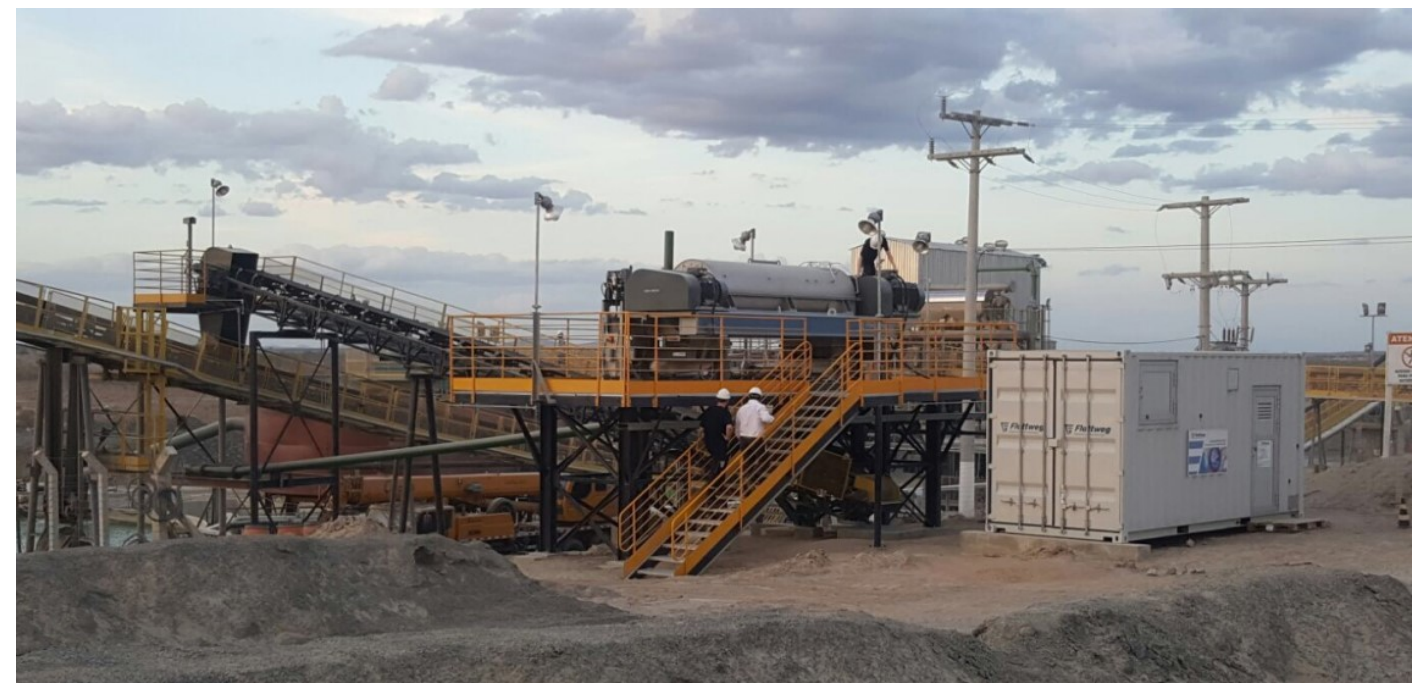

Figure 12 Centrifuge installation at Braúna mine
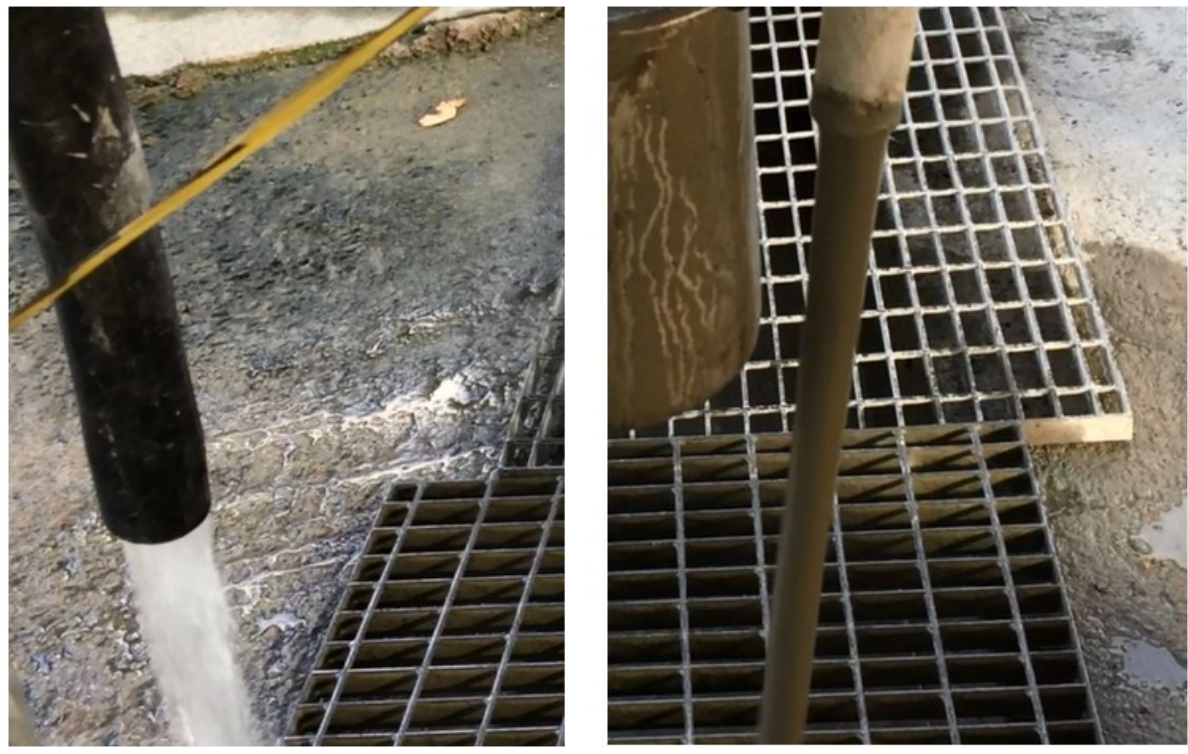

Figure 13 Centrate discharge and feed material

The solids discharge can be seen in Figure 14. These solids are blended with the screened hydrocyclone underflow. This material is then loaded onto trucks as shown in Figure 15. The blended material is then transported to a dump site. As there are no hazardous components contained in the solids or residual moisture, the material does not need to be impounded.

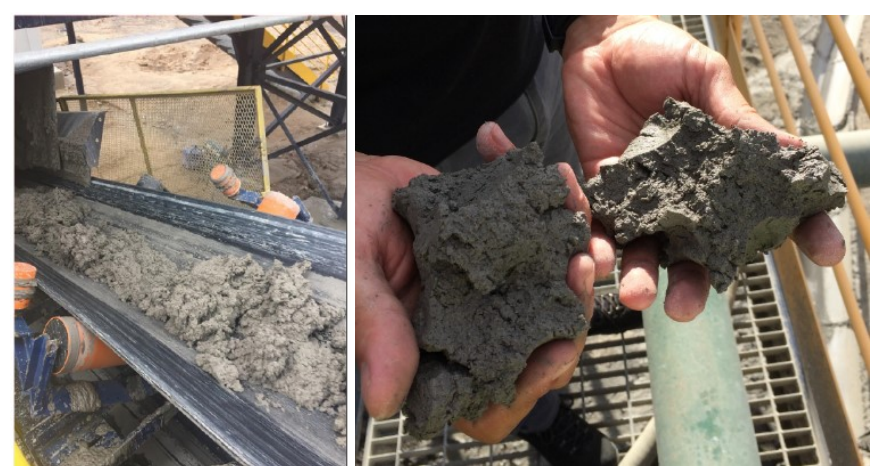

Figure 14 Solid discharge from centrifuge 


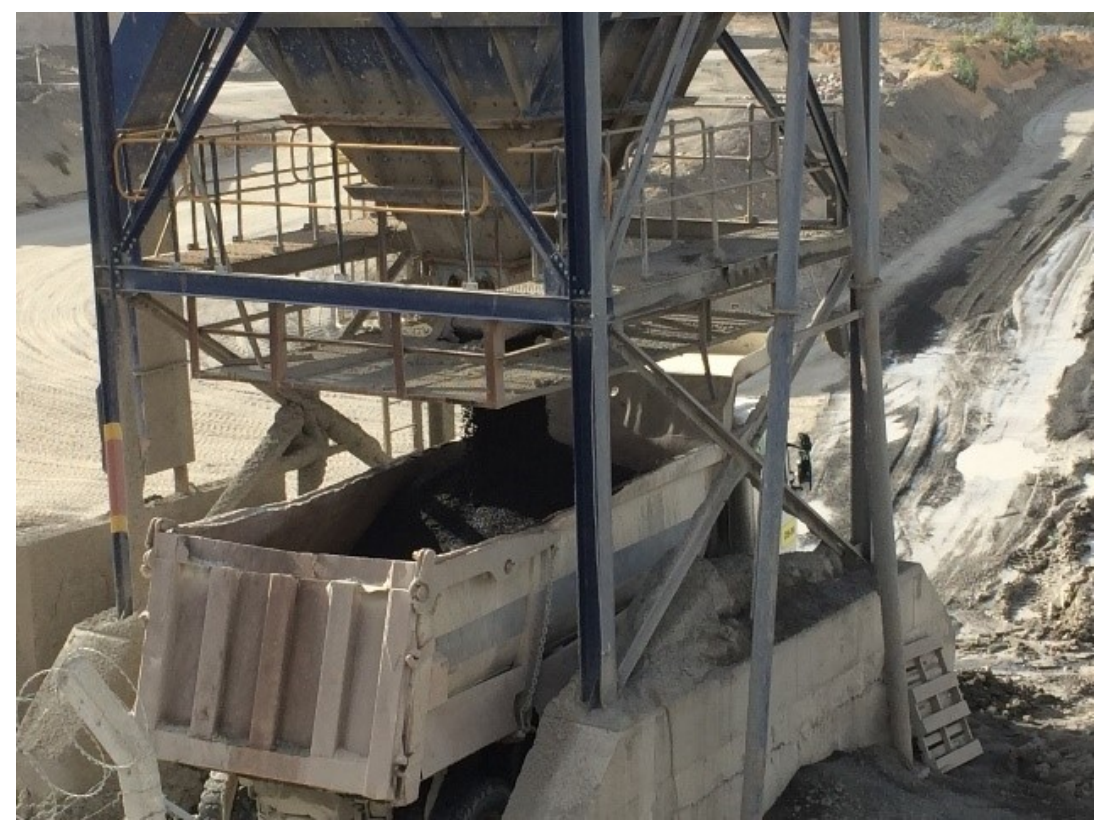

Figure 15 Solid discharge into truck after mixing underflow of hydrocyclone and solid of centrifuge, no addition of any surcharge material required

The operating parameters of the centrifuge are shown in Table 3 and the particle size analysis is shown in Figure 16.

Table 3 Operating parameters at Braúna mine

\begin{tabular}{ll}
\hline Parameter & Value \\
\hline Feed flow rate & Up to $70 \mathrm{~m}^{3} / \mathrm{hr}$ \\
Feed solid concentration & $45 \%$ (by wt) \\
Solids feed rate & Up to $36.7 \mathrm{t} / \mathrm{hr}$ \\
Drum speed & $930 \mathrm{rpm}$ \\
Centrifugal force & $4,365 \mathrm{~m} / \mathrm{s}^{2}$ (445 $\left.\times \mathrm{g}\right)$ \\
Solids in centrate & $<500 \mathrm{ppm}$ \\
Solids concentration in cake & $60-65 \% \mathrm{w} /$ flocculant, $72 \% \mathrm{w} / \mathrm{o}$ flocculant (by mass) \\
Operational power consumption & $30 \mathrm{~kW} \mathrm{main} \mathrm{drive,} 25 \mathrm{~kW}$ scroll drive \\
Flocculant consumption & $0.2-0.6 \mathrm{~kg} / \mathrm{t}$ dry matter \\
\hline
\end{tabular}




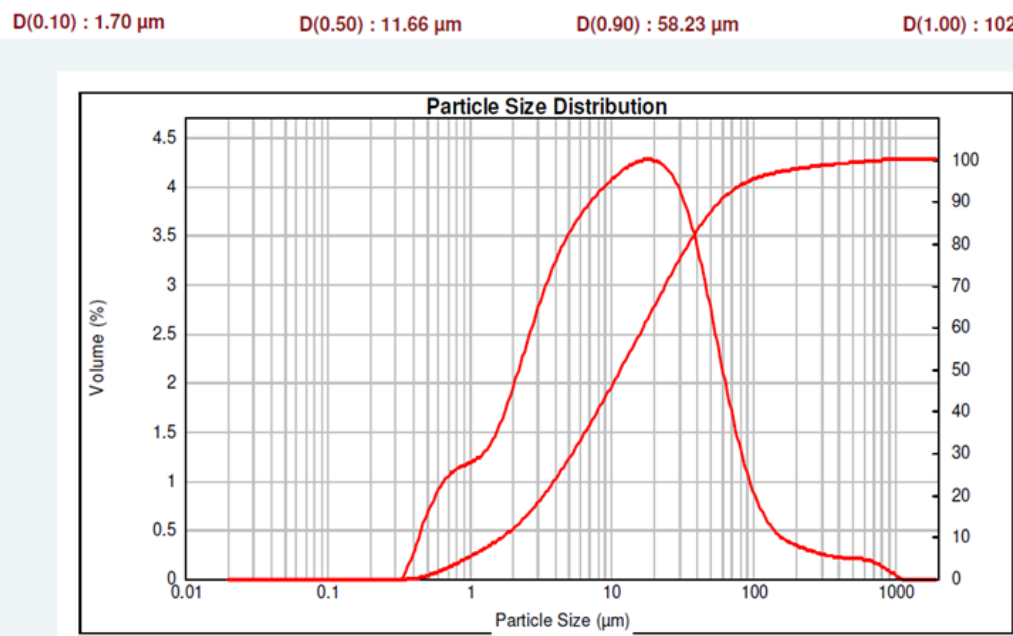

Particle size distribution

Figure 16 Particle size distribution of tailings at Lipari's Braúna diamond mine

\subsection{Case study - Southern Copper, Peru}

Southern Copper is operating two large open pit copper mines (Cuajone and Toquepala) in the area of Moquegua, at an elevation of about 3,200 m. At present, floatation tailings are disposed of via a $54 \mathrm{~km}$ long drainage 'channel', as shown in Figure 17, descending 2,000 $\mathrm{m}$ down the mountainside to a tailings dam. The channel consists in part of concrete-lined spillways and in part of natural ravines with no lining whatsoever.

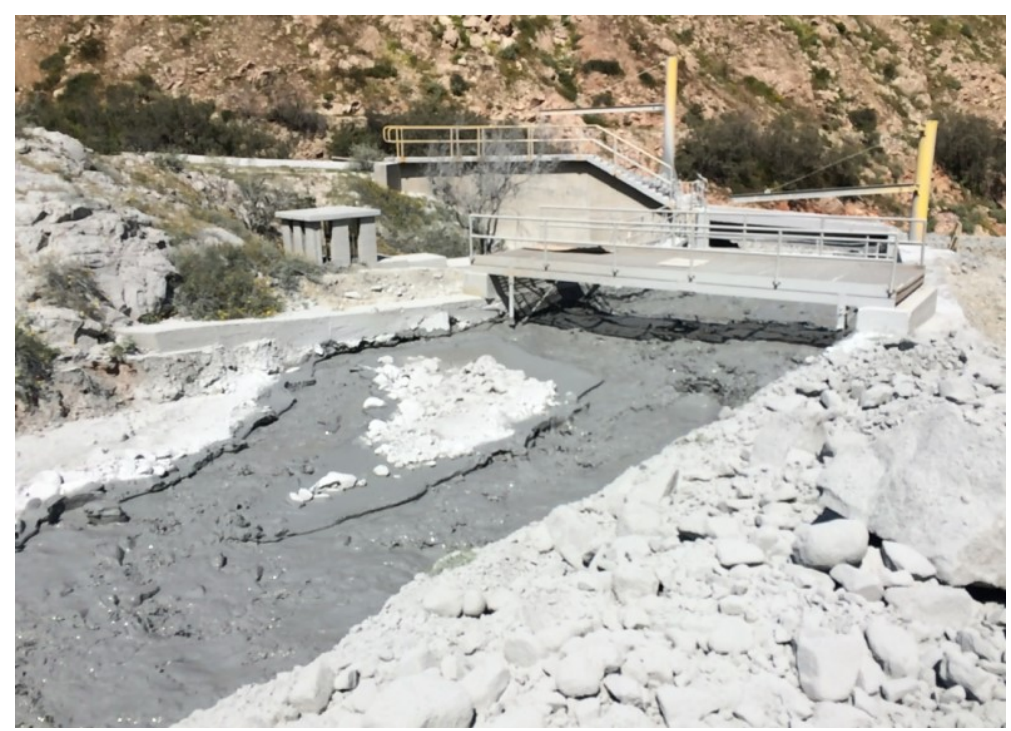

Figure 17 Existing tailings stream at Cuajone mine

Apart from the obvious environmental issues this raises, the mine has to meet regulations requiring the recovery and reuse of a major portion of the process water carried away with the tailings. In order to achieve this, a portion of the water is recovered from the settled tailings and pumped back up to the mine. At least $40 \%$ of the water is, however, lost to evaporation and seepage.

The long-term plan is to dewater the tailings and dry stack the solids on a site much closer to the mine. In the meantime, Southern Copper are investigating the option of recovering a greater portion of the water at the tailings dam. To this purpose, trials were conducted using a Flottweg Z92-4 centrifuge to dewater thickened tailings. The test installation is shown in Figure 18. 


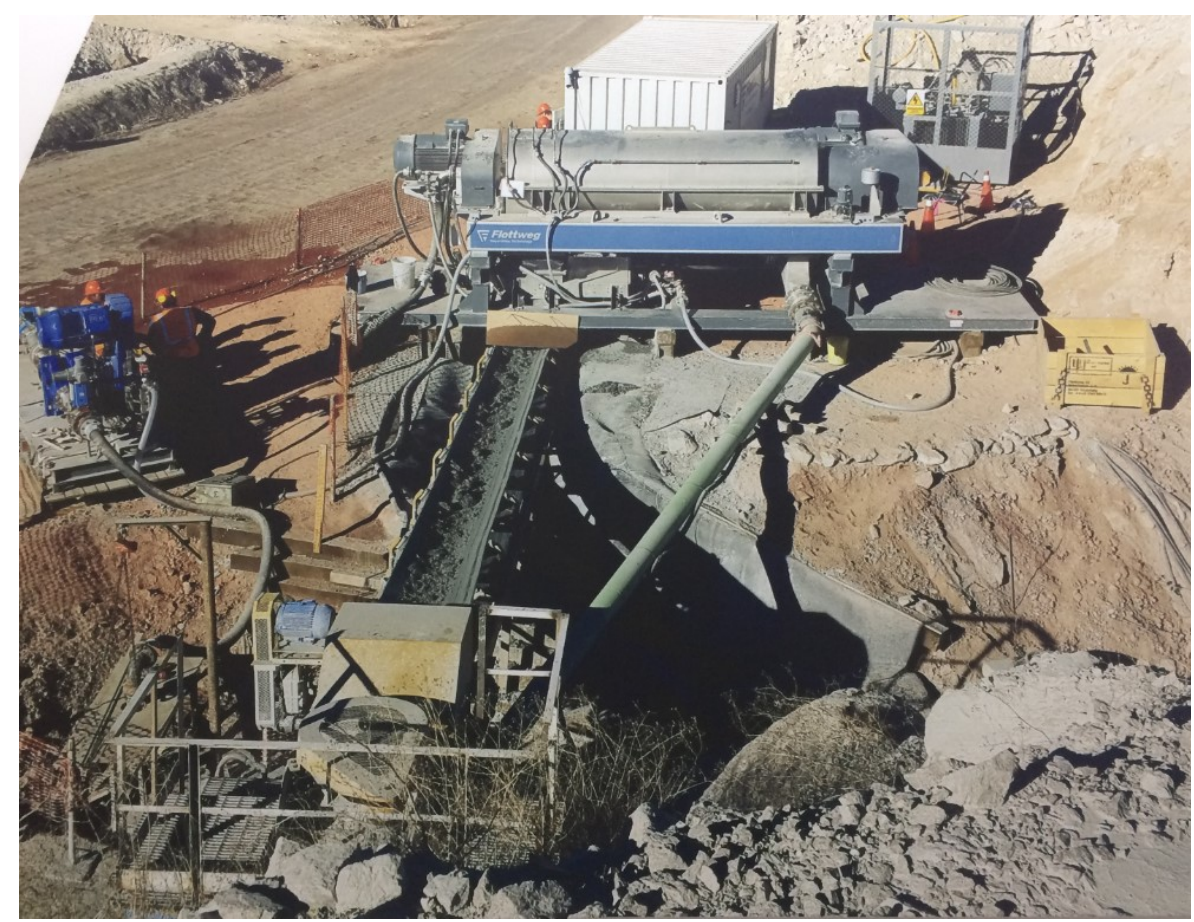

Figure 18 Centrifuge installation at Cuajone mine

Figure 19 shows the feed material and the centrate obtained by laboratory spin tests.

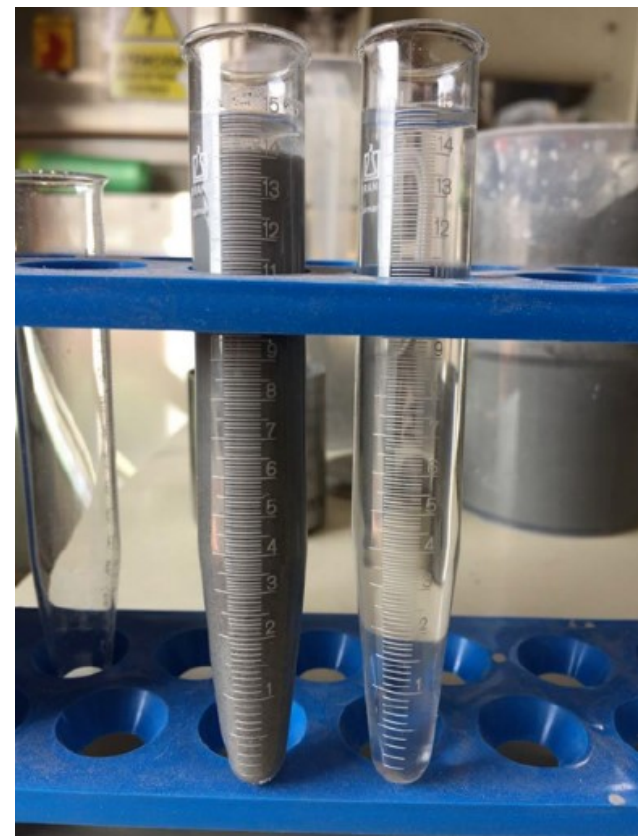

Figure 19 Feed and centrate discharge at Cuajone mine (lab test centrifuge $9,810 \mathrm{~m} / \mathrm{s}^{2}(1,000 \times \mathrm{g})$ for one minute)

Full-scale centrifuge tests proved very successful. A clear centrate and a solids discharge containing up to $81 \%$ dry solids was achieved. The solids discharged from the centrifuge are shown in Figure 20 . It is notable that the decanter centrifuge was able to achieve this at a very low centrifugal force of only $5,101 \mathrm{~m} / \mathrm{s}^{2}$ or $520 \times \mathrm{g}$. This is an extremely positive result as at such low forces the wear on the scroll flight in the machine would be minimal. Operating parameters are shown in Table 4. 


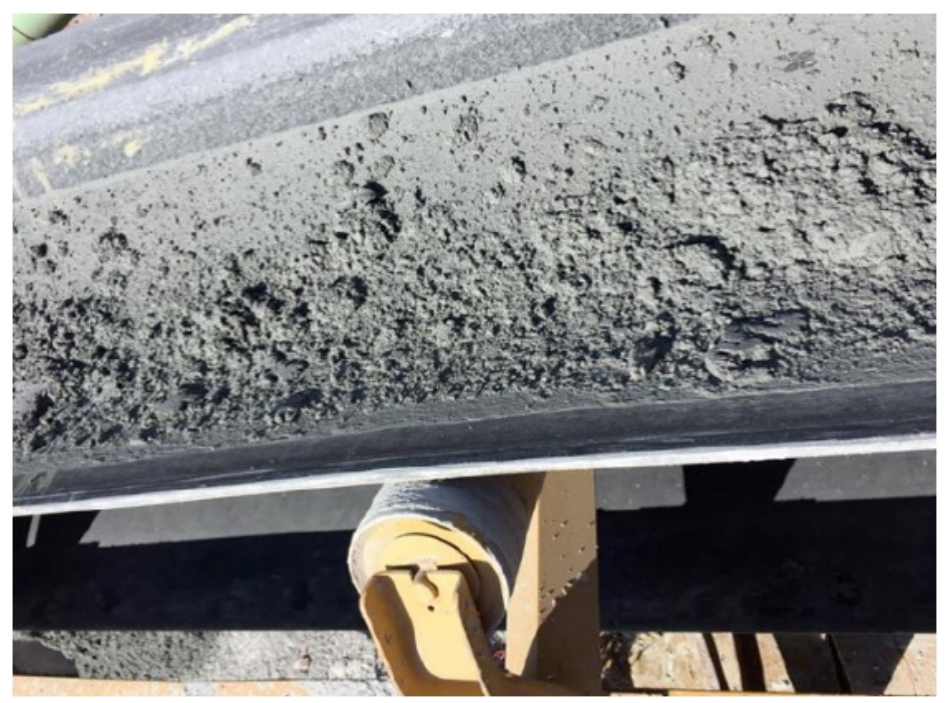

Figure 20 Centrifuge cake discharge at Cuajone mine

Table 4 Operating parameters at Cuajone mine

\begin{tabular}{ll}
\hline Parameter & Value \\
\hline Feed flow rate & Up to $60 \mathrm{~m}^{3} / \mathrm{hr}$ \\
Feed solid concentration & $53 \%$ by wt \\
Solids feed rate & Up to $50 \mathrm{t} / \mathrm{hr}$ \\
Drum speed & $1,000 \mathrm{rpm}$ \\
Centrifugal force & $5,101 \mathrm{~m} / \mathrm{s}^{2}(520 \times \mathrm{g})$ \\
Solids in centrate & $>500 \mathrm{ppm}$ \\
Solids concentration in cake & $81 \% \mathrm{w} / \mathrm{flocculant}, 76 \% \mathrm{w} / \mathrm{o}$ flocculant (by mass) \\
Operational power consumption & $40 \mathrm{~kW}$ main drive, $35 \mathrm{~kW}$ scroll drive \\
Flocculant consumption & $0.1-0.2 \mathrm{~kg} / \mathrm{t}$ dry matter \\
\hline
\end{tabular}

\section{Conclusion}

The use of centrifuges for dewatering tailings is a viable alternative to existing technologies. Based on environmental impact, space requirement and investment cost, the mechanical separation of solids and liquids by centrifugal force will find its way increasingly into modern mining and minerals processing operations.

\section{Acknowledgement}

The authors thank the mentioned companies for their support to test a new technology.

\section{References}

Davies, MP \& Rice, S 2001, 'An alternative to conventional tailing management: "dry stack" filtered tailings', Proceedings of the Eighth International Conference on Tailings and Mine Waste, A.A. Balkema, Rotterdam, pp. 411-422.

ENVITES, spol. s r.o. 2019, Graph of Filtration Cycle, online image, viewed 21 March 2019, https://www.envites.cz/en/products/ filter_presses/with_chamber_plates/filtration_in_the_chamber_filter_press

Patagonia Under Siege 2018, Kinross Gold, Owner of the Espolon Claim, Prepares Ground for Cyanide Heap Leaching in Alaska's Biggest Gold Mine - Environmental Challenge Expected, http://patagonia-under-siege.blogspot.com/2007/11/kinross-goldowner-of-espolon-claim.html 
